\title{
COnE).(OES
}

CIÊNCIA E TECNOLOGIA

\section{METODOLOGIAS ALTERNATIVAS NA PERSPECTIVA DO DOCENTE DE CIÊNCIAS DA NATUREZA E MATEMÁTICA}

\author{
Maria Alcilene Gomes de Menezes Silva ${ }^{1}$, Lilianne de Sousa Silva ${ }^{1}$, \\ Luciana Medeiros Bertini ${ }^{1}$, Leonardo AlCÂntara Alves ${ }^{1}$ \\ ${ }^{1}$ Instituto Federal de Educação, Ciência e Tecnologia do Rio Grande do Norte - IFRN \\ <alcilenejr@hotmail.com><liliannepalhano@gmail.com><luciana.bertini@ifrn.edu.br> \\ $<$ leonardo.alcantara@ifrn.edu.br> \\ DOI: <https://doi.org/10.21439/conexoes.v14i3.1403>
}

\begin{abstract}
Resumo. As metodologias alternativas são estratégias pedagógicas utilizadas pelos docentes para tentar tornar os processos de ensino e de aprendizagem mais significativos para os discentes. Com este foco, o presente artigo tem como objetivo principal verificar quais as perspectivas dos docentes das áreas de Ciências da Natureza e Matemática sobre essas estratégias. Para tanto, aplicamos uma escala de Likert, contendo 21 afirmativas, com os professores das duas áreas em duas escolas da rede estadual de ensino de Apodi/RN, uma escola localizada na Zona Rural e uma da Zona Urbana. Após aplicação da pesquisa e análise dos dados, observamos que os docentes defendem que o uso de metodologias alternativas pode beneficiar a aprendizagem dos alunos. Concluímos ainda que, para os docentes participantes da pesquisa, a metodologia alternativa é um auxílio nos processos cognitivos do aluno, além de ser fator motivador, ajudando também na construção do conhecimento em sala de aula.
\end{abstract}

Palavras-chaves: Metodologias alternativas. Aprendizagem Significativa. Prática docente.

Abstract. Alternative methodologies are pedagogical strategies used by teachers to try to make the teaching and learning processes more meaningful for students. With this focus, the present article has as main objective to verify the perspectives of the teachers of Natural Sciences and Mathematics areas on these strategies. To do so, we applied a Likert scale, containing 21 affirmations, with the teachers of the two areas in two schools in the Apodi/RN state school system, one school located in the Rural Zone and one in the Urban Zone. After applying the research and data analysis, we observed that teachers argue that the use of alternative methodologies can benefit students' learning. We conclude that, for the teachers participating in the research, the alternative methodology is an aid in the students' cognitive processes, besides being a motivating factor, also helping in the construction of knowledge in the classroom.

Keywords: Alternative methodologies. Significant Learning. Teaching practice.

\section{INTRODUÇÃO}

Atualmente contamos com estudiosos interessados em identificar alternativas eficientes de ensino que possibilitem o desenvolvimento das habilidades críticas dos educandos, presente na literatura. Em consonância com o pensamento de Freire (1996, p. 21) de que "ensinar não é transferir conhecimento, mas criar as possibilidades para sua produção ou sua construção", o educador deverá optar em utilizar diferentes formas de efetivar o processo de ensino e de aprendizagem, considerando que o educando não é apenas o simples objeto de trabalho docente, mas deve ser entendido como sujeito, que faz parte ativa deste processo.

As teorias educacionais defendem que o educando deve ser agente ativo no processo de construção de seus próprios conhecimentos, visto que essa construção se dará a partir da desestruturação de antigos saberes (oriundos do senso comum) agregado ao surgimento de novas ideias (conhecimento científico). Portanto, para que esse processo ocorra de forma satisfatória faz-se necessário que os sujeitos envolvidos, educador e edu- 
cando, estejam motivados a construir o conhecimento. Assim, aulas que motivem e facilitem o aprendizado se fazem necessárias.

O uso de metodologias alternativas pode ser apontado, dentre outras ferramentas, como um caminho para a realização do processo de ensino e de aprendizagem, em que os educandos estejam motivados a participar ativamente desse processo, objetivando uma aprendizagem significativa. Essas metodologias facilitam que novas informações sejam ancoradas em um subsunçor ${ }^{1}$ pré-existente na estrutura cognitiva do aluno.

Para Castro e Costa (2011, p. 4), um exemplo de metodologia alternativa, os jogos, "são uma alternativa viável e interessante para aprimorar as relações entre professor-aluno- conhecimento". Segundo as autoras, essa metodologia traz como vantagem a possibilidade de motivação dos alunos para participarem espontaneamente das aulas. Podendo ainda citar como exemplos de metodologias alternativas o uso dos objetos de aprendizagem, das gincanas, aulas de campo, pesquisas e laboratório de informática, que se constituem como metodologia alternativa quando visa o aluno como construtor do seu conhecimento.

Com isto, o desenvolvimento dessa pesquisa se dá em razão de que, mesmo com os trabalhos já realizados que tratam do tema Metodologias Alternativas como ferramenta que auxilia o professor nos processos de ensino e de aprendizagem, através de análise realizada pelos autores sobre o tema, poucos são os que discutem o assunto a partir das perspectivas dos docentes. Por isso, nosso interesse em realizar essa discussão, visto que são estes que aplicarão ou não as metodologias alternativas em suas práticas. Fazemos aqui uma análise quantitativa das concepções dos professores das Áreas de Ciências da Natureza e Matemática em relação às metodologias alternativas com um olhar para a aprendizagem significativa.

Entendemos as áreas citadas como distintas, no que se refere às competências do saber ensinar, porém, passivas de igualdade quando tratamos dos relatos das dificuldades dos alunos em construírem conhecimento e motivação para aprendizagem, segundo a literatura e experiências profissionais dos autores. Sendo assim, iniciaremos nosso artigo abordando as concepções encontradas na literatura sobre a prática docente e as metodologias alternativas. Em seguida, traremos nossa análise dos dados coletados das concepções dos docen-

${ }^{1} \mathrm{O}$ subsunçor, segundo à teoria da Aprendizagem Significativa de Ausubel, trata-se do conhecimento prévio dos alunos, ao qual uma nova informação pode se integrar ao cérebro humano (PELIZZARI et al., 2002).

\section{tes sobre o tema.}

\section{O TRABALHO DOCENTE}

A definição do trabalho do professor é cercada de incertezas. Não se tem conceitos prontos e definitivos, apenas conceitualizações provisórias que vão se construindo e descontruindo no confronto com as pesquisas realizadas. $\mathrm{O}$ trabalho docente, a partir de uma consideração baseada na pesquisa, vem ao longo dos anos ganhando destaque nos estudos na área educacional, visto a necessidade de superação de antigos conceitos e verdades sobre essa prática como, por exemplo, a associação da prática docente ao sacerdócio e a ideia de que a docência era tida como um dom.

Para compreendermos a dimensão do trabalho do professor é preciso saber que além do trabalho efetivamente realizado, devemos levar em consideração o trabalho prescrito - conjunto de normas e regras projetadas que regulam as ações, e trabalho planificado conjunto de tarefas, seus objetivos, suas condições materiais e sua forma de desenvolvimentos das ações projetadas (MACHADO, 2003).

A educação contemporânea apresenta desafios ao trabalho do professor. Primeiro, pela necessidade da formação de cidadãos condizentes com as exigências da sociedade atual quanto a formação de profissionais para atuar nos diversos seguimentos da sociedade, que possam trabalhar em grupo e que sejam proativos, por exemplo. Segundo, porque ela é pautada na prática docente, que considera o professor e aluno como sujeitos da aprendizagem e busca a superação do ensino tradicional $^{2}$ que envolve o aluno no processo educacional como objeto e o professor como detentor de conhecimento. Pimenta (1999, p. 23) acrescenta que:

\footnotetext{
A finalidade da educação escolar na sociedade tecnológica, multimídia e globalizadora é possibilitar que os alunos trabalhem os conhecimentos científicos e tecnológi$\cos$, desenvolvendo habilidades para operá-los, revê-los e reconstruí-los com sabedoria. O que implica analisálos, confrontá-los, contextualizá-los. Para isso, há que os articular em totalidades que permitam aos alunos irem construindo a noção de "cidadania mundial".
}

\footnotetext{
${ }^{2}$ Neste trabalho quando mencionamos a necessidade da superação do ensino tradicional ou modelo tradicional de ensino, nos referimos ao entendimento do ensino de forma unidirecional, o aluno é entendido apenas como objeto do processo de ensino-aprendizagem e o professor como o único sujeito desse processo, que expõe o conteúdo com o intuito do aluno ser apenas um ouvinte passivo. Não desconsideramos metodologias que mesmo sendo habituais possibilitam a reflexão do alunado, permitindo a construção de conhecimento de forma potencialmente significativa, o aluno passa a assumir um papel de sujeito no processo de ensino e de aprendizagem.
} 
Essa nova visão de educação influencia diretamente na prática docente. Prática essa que é uma construção contínua e diária e que, de acordo com a ideia de Tardiff (2002, p. 38), os professores "no exercício de suas funções e na prática de sua profissão, desenvolvem saberes específicos, baseados em seu trabalho cotidiano e no conhecimento de seu meio". Diante deste pensamento, faz-se necessário que o professor reveja sua maneira de conduzir sua ação e reflita sobre ela.

O trabalho docente é responsável em formar indivíduos completos, críticos e transformadores da realidade em que estejam inseridos. É importante ressaltar que existem condicionantes que envolvem a própria ação docente, entre esses, citamos os saberes teóricos e práticos, saberes esses plurais e heterogêneos, que veem à tona na prática profissional.

Levando em consideração o exposto acima e sabendo que a educação se apoia em uma concepção de homem a ser formado de acordo com os anseios da sociedade e que essa necessidade se modifica em função da época, vale ressaltar que cabe ao professor ter a clareza da concepção pedagógica que orientará o processo de ensino e de aprendizagem no cotidiano de sua prática.

Ao analisar a prática docente dos professores das áreas de Ciências da Natureza e Matemática, é notável que estes profissionais têm por responsabilidade possibilitar a construção dos conhecimentos pelos discentes de maneira que estes sejam cidadãos com conhecimentos necessários para entender os debates públicos sobre as questões de ciência e tecnologia, tendo em vista, que é afirmado pelos documentos da Unesco (2005, p. 52) que "A educação científica, em todos os níveis e sem discriminação, é requisito fundamental para a democracia".

Na perspectiva de Moran, Masetto e Behrens (1006) quando se fala no contexto educacional moderno e tecnológico, é importante que o professor desenvolva metodologias de ensino que incentivem a participação dos alunos para que tenham uma boa aprendizagem e produzam uma relação de interação, baseada na pesquisa, no debate e no diálogo.

O desenvolvimento de metodologias alternativas deve ocorrer, principalmente, quando se leva em consideração os avanços científicos e tecnológicos, os quais exigem dos professores de Ciências da Natureza e Matemática (bem como os demais) a busca de metodologias de ensino cada vez mais modernas e diligentes. Isso, por sua vez, reflete diretamente no trabalho docente, exigindo uma formação inicial e continuada que aborde novas perspectivas e concepções de ensino, a fim de proporcionar aos docentes em atuação, uma reflexão sobre a sua própria prática a partir da utilização de materiais alternativos.

Reafirmando o que defende Freire (1996, p. 24) "a reflexão crítica sobre a prática se torna uma exigência da relação Teoria/Prática sem a qual a teoria pode ir virando blá-blá-blá e a prática, ativismo", destaca-se então, a necessidade da criação de metodologias diferenciadas da convencional por professores das áreas mencionadas anteriormente, por serem, muitas vezes, consideradas desvinculadas do dia-a-dia e da realidade em que os alunos se encontram.

A motivação do aluno tem muito a ver com a contextualização, pelo fato de dar sentido ao que ele aprende, fazendo com que relacione o que está sendo ensinado com sua experiência cotidiana. Através da contextualização, é possível que o aluno faça uma ponte entre teoria e a prática, o que é previsto na Lei de Diretrizes e Bases da Educação - LDB no 9.394/96 (BRASIL, 1996) e nos Parâmetros Curriculares Nacionais (BRASIL, 1998).

É importante destacar que os instrumentos utilizados na prática educativa são de importância para a formação de significados social, político e cultural dos conteúdos programáticos propostos pelos Parâmetros Curriculares Nacionais para o Ensino Médio - PCNEM. Para que os alunos participem ativamente, é indispensável que as instituições de ensino priorizem condições para a ocorrência de um aprendizado significativo (NUNES; ARDONI, 2009). Desta forma, os alunos serão motivados a apreender e fazer as suas próprias relações entre conteúdo e o seu cotidiano.

\section{METODOLOGIA}

A pesquisa em questão, foi desenvolvida em duas escolas da rede estadual de ensino do Rio Grande do Norte, uma localizada na Zona Rural (ZR) e outra na Zona Urbana (ZU) do Município de Apodi. As escolas em questão fazem parte da $13^{\mathrm{a}}$ Diretoria Regional de Educação e Cultura - DIREC do Rio Grande do Norte que, por sua vez, atende os municípios de Apodi, Felipe Guerra, Severiano Melo, Rodolfo Fernandes, Caraúbas, Itaú e Tabuleiro Grande, conforme Figura 1.

O público alvo da pesquisa foi um total de dezesseis (16) professores atuantes no ensino das escolas campo de pesquisa das áreas de Ciências da Natureza e Matemática, sendo quatro (04) docentes, correspondente a $25 \%$ do total do corpo de magistério, da Escola localizada na Zona Rural (ZR) do município de Apodi/RN e doze (12) professores, correspondente a 75\% do total do corpo de magistério, da escola campo de pesquisa da 


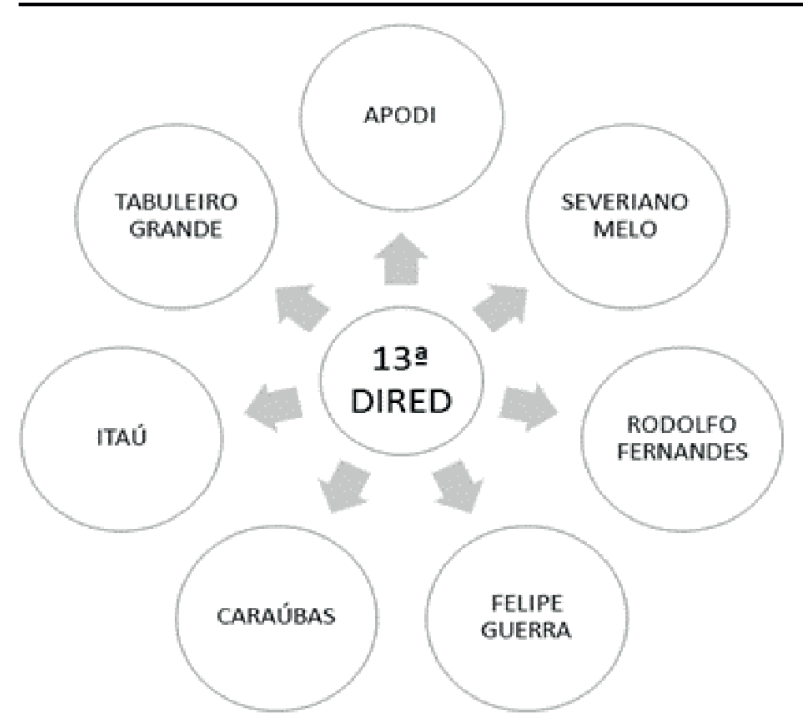

Figura 1: Municípios atendidos pela $13^{\mathrm{a}}$ DIRED

Fonte: Produzido pelos autores (2017).

Zona Urbana (ZU). Entre os docentes participantes do estudo das duas escolas campo de pesquisa temos sete (07) professores que ministram aulas somente da disciplina de Matemática, dois (02) professores somente aulas de Física, três (03) docentes somente de Química, três (03) professores somente da disciplina de Biologia e um (01) professor que atua em aulas das disciplinas de Física e Química.

Com intuito de conhecer como os docentes das áreas de Ciências da Natureza e Matemática nas escolas compreendem as metodologias alternativas como uma ferramenta facilitadora ou não do processo de ensino e de aprendizagem realizou-se a aplicação de um teste utilizando a escala de Likert.

É importante destacar que as escolas escolhidas para o estudo, possuem realidades educativas diferenciadas com o público alvo que se diferencia pelas realidades vividas, práticas extraescolares, cultura e possíveis relações do conteúdo com o dia-a-dia. Desta forma, a fim de uma coleta de dados que não privilegie um contexto em especifico, foram escolhidas duas escolas em localidades diferentes.

Já em relação à escolha da utilização da escala de Likert para obtenção desses dados, ocorreu pelo fato desse tipo de instrumento permitir o registro do nível de concordância ou discordância com uma declaração dada e ser recomendada quando se pretende avaliar atitudes mais específicas (GARCÍA; GALÁN, 1998). É importante destacar que cada afirmativa possui um valor correspondente, para concordo totalmente (peso +2 ), concordo (peso +1 ), indeciso (peso 0 ), discordo (peso -1) e discordo totalmente (peso -2). Os dados obtidos pela aplicação da escala de Likert foram tratados utilizando a abordagem quantitativa de Costa (2010) que estabelece:

- Média Aritmética:

$$
\mu=\frac{\sum x_{i}}{N}
$$

Onde,

$\mu=$ Média;

$\sum x_{i}=$ Soma de números;

$N=$ Quantidade de números somados.

- Desvio Padrão (s)

$$
s=\sqrt{\frac{\sum\left(x_{i}-\mu\right)^{2}}{n-1}}
$$

Onde,

$S=$ Desvio padrão;

$x_{i}=$ Valor correspondente a afirmativa de cada participante;

$\mu=$ Média Aritmética;

$n=$ Número total de participante.

\section{RESULTADOS E DISCUSSÃO}

As discussões dos dados foram realizadas de forma separada nas escolas campo de pesquisa, a fim de diagnosticar a visão dos docentes que atuam em localidades diferenciadas. As assertivas constituintes da escala de Likert totalizam em vinte e uma (21), objetivando abordar as seguintes categorias de análise dos resultados:

- Categoria 01 - A prática docente e as metodologias alternativas (A1 - A6);

- Categoria 02 - As metodologias alternativas no processo de efetivação da aprendizagem (A7 A15);

- Categoria 03 - As atitudes dos docentes quanto o uso de metodologias alternativas (A16 - A21).

Após análise dos dados e cálculo das médias e desvio padrão para cada assertiva, os resultados discutidos e apresentados em gráficos. 


\subsection{A Prática Docente e as Metodologias Alternati- vas}

Os dados da primeira categoria de análise, a prática docente e as metodologias alternativas (A1 - A6), estão representados na Figura 2 e Tabela 1.

Tabela 1: Dados obtidos da Zona Rural e Urbana - Categoria 01

\begin{tabular}{ccc}
\hline Assertivas & $\begin{array}{c}\text { Concepções- } \\
\text { Zona Rural } \\
\text { (Média } \circ \text { Desvio) }\end{array}$ & $\begin{array}{c}\text { Concepções- } \\
\text { Zona Urbana } \\
(\text { Média } \circ \text { Desvio) }\end{array}$ \\
\hline $\mathrm{A} 1$ & $0,25 \circ 1,50$ & $0,55 \circ 1,51$ \\
$\mathrm{~A} 2$ & $1,00 \circ 1,41$ & $0,73 \circ 1,01$ \\
$\mathrm{~A} 3$ & $1,00 \circ 1,41$ & $0,91 \circ 0,83$ \\
$\mathrm{~A} 4$ & $0,25 \circ 2,06$ & $0,73 \circ 1,05$ \\
$\mathrm{~A} 5$ & $1,25 \circ 0,50$ & $1,00 \circ 0,77$ \\
$\mathrm{~A} 6$ & $0,25 \circ 1,50$ & $1,00 \circ 1,00$ \\
\hline
\end{tabular}

Fonte: Produzido pelos autores (2017)

O primeiro bloco da escala de Likert objetivou conhecer como os docentes compreendem sua prática e as metodologias diferenciadas do habitual, como médias obtidas de ZR 0,25 e ZU 0,55 (A1). A partir do valor do desvio padrão, relativamente alto, de ZR Desvio 1,5 e ZU Desvio 1,51, percebe-se uma dispersão significativa entre os respondentes, o que nos diz que parte dos docentes tanto da Zona Rural como da Zona Urbana, apontam que sua formação inicial foi insuficiente para sua atuação em sala de aula, conforme os dados obtidos, e outros, que a sua formação inicial foi suficiente como suporte para sua prática.

De modo geral, neste primeiro posicionamento da análise de assertivas, percebe-se que existem docentes que saem das Instituições de Ensino Superior-IES, com inseguranças quanto a atuação em sala de aula, relacionada com a dificuldade de articulação entre teoria e prática docente, a fim de produzir a sua própria identidade como profissionais. Essa insegurança é gerada pela concepção antiga de que o professor é o detentor do conhecimento que será transmitido ao aluno (ZABALZA, 2004). Para Fávero (1992), o conhecimento de teorias ou o reconhecimento dos problemas da profissão ainda se mostram insuficientes para uma formação do profissional docente, sendo necessário desenvolver, ainda como licenciando, um posicionamento crítico a partir de subsídios fornecidos pelos cursos de graduação.

Leva-se em consideração que, muitas vezes, os objetivos propostos antes da prática, ou seja, em seu planejamento, podem sofrer influências do contexto e que as dimensões do trabalho docente variam conforme os objetivos propostos e os efetivamente alcançados. No trabalho de Lousada (2004) se destaca a necessidade de entender o ensino a partir das dimensões do trabalho docente, como forma de entender a ação do trabalhador (o professor). O trabalho prescrito pode ser considerado como a tarefa dada, prescrita pela instituição, o realizado é o trabalho efetivamente feito e o real compreende, além das atividades realizadas, todas as tarefas não realizadas.

Com o objetivo de melhorar a ação do professor em aula, inúmeras metodologias têm sido apresentadas no âmbito das pesquisas em ensino, porém, cabe salientar que diversos aspectos do trabalho docente estão sendo esquecidos, tais como as dimensões de sua atividade profissional (trabalho prescrito, realizado e real) e as concepções docentes sobre o uso destas metodologias. Acredita-se, em um ponto de vista mais amplo, que o trabalho docente tem suas raízes na formação inicial, nas Instituições de Ensino Superiores, que na maioria das vezes, não condiz com a realidade das escolas públicas brasileiras e somente na prática docente ocorrerá a consolidação de tais formações, que colocaram à prova os conhecimentos adquiridos na graduação, alguns autores chamam esse período inicial da prática docente de "choque com a realidade"(SILVA, 1997).

Ressalta-se ainda, a necessidade da busca por novos conhecimentos, por parte dos professores, pois o trabalho docente e seus aspectos disciplinares, não podem ser vistos como receita e ser desenvolvida em qualquer circunstância e/ou contexto. Reafirma-se aqui, a importância de metodologias diferenciadas, que objetivem atender a necessidade de um público em específico, diferenciando o objetivo que se quer alcançar, segundo contexto e o perfil dos alunos.

Os docentes das duas escolas acreditam que as metodologias utilizadas em sala de aula influenciam diretamente a aprendizagem, médias ZR 1,0 e ZU 0,73 (A2). Sendo que os respondentes afirmaram que utilizam com frequência essas metodologias, média ZR 1,0 e ZU 0,91 (A3), porém as escolas não oferecem todas as condições necessárias ao desenvolvimento de aulas com metodologias alternativas, média ZR 0,25 e ZU 0,73 (A4). Tais assertivas apresentaram desvio padrão superior as médias obtidas, o que nos diz, que houve opiniões diferenciadas entre si, com exceção o valor da medida de dispersão da assertiva A3 da ZU, que é menor do que a média (Desvio padrão de 0,83 ). Isto revela que as opiniões dos participantes estão em consonância de que os docentes da Zona Urbana usam metodologias diferentes do convencional com menos frequência da que os docentes da Zona Rural. 


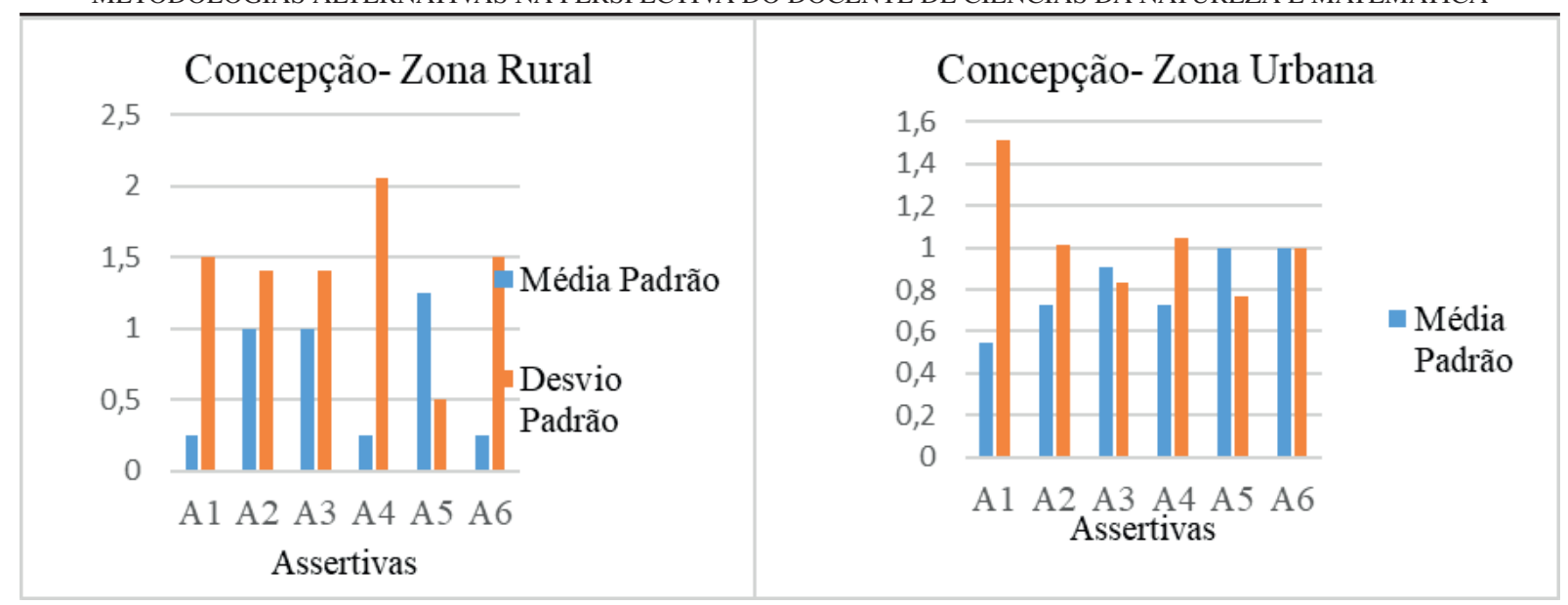

Figura 2: Concepções dos docentes da Zona Rural e Urbana - Categoria 01 Fonte: Produzido pelos autores (2017).

Acredita-se que isso ocorra, devido à possível sensibilidade dos docentes da Zona Rural em relação a aspectos da diversidade e da situação histórica particular da comunidade que exigem que o professor utilize estratégias que ajudem a reafirmar identidades do campo, em conformidade as palavras de Arroyo, Caldart e Molina (2004) que defendem que o objetivo principal da escola rural é de proporcionar conhecimentos, cidadania e continuidade cultural.

As médias obtidas vão ao encontro das discussões realizadas anteriormente. Destaca-se aqui novamente que é necessário a conscientização da comunidade escolar da importância de condições favoráveis à pratica docente diferente do habitual, a fim de motivar os alunos para a construção de conhecimentos e que os docentes participantes da pesquisa, apesar de possuírem realidades de ensino diferenciadas, valorizam a utilização de metodologias alternativas como instrumento potencialmente significativo e que estes, possivelmente, contribuem para atender a função primordial da escola citada por Leite (1999).

\section{A função primordial da escola é ensinar, transmitir va- lores e traços da história e da cultura de uma sociedade. A função da escola é permitir que o aluno tenha visões diferenciadas de mundo e de vida, de trabalho e de pro- dução, de novas interpretações de realidade, sem, con- tudo, perder aquilo que lhe é próprio, aquilo que lhe é identificador (LEITE, 1999, p. 99).}

Neste sentido, a função da escola deve ser desenvolvida à medida que os seus objetivos sejam alcançados independente de sua localidade - Rural/Urbano. Desta forma, deve ser levado em consideração o con- texto escolar e toda estrutura econômica, política, histórica, cultural e social, que influenciam diretamente o fazer docente, possibilitando assim, um ensino contextualizado.

Os docentes participantes da pesquisa sustentam uma perseverança para a utilização de metodologias alternativas por acreditarem em sua potencialidade para a construção de significados na aprendizagem dos sujeitos envolvidos no processo de ensino- aprendizagem, conforme os resultados apresentados, mesmo enfrentando diversas dificuldades para a execução do seu trabalho, como por exemplo: a falta de assistência pedagógica e adequadas condições objetivas de trabalho, as necessidades de gestão de tempo e lacunas na formação inicial (PARO, 2012).

Quando reporta-se ao planejamento coletivo, os docentes afirmaram que as escolas destinam esses momentos para a organização de aulas com metodologias alternativas (média ZR 1,25 e ZU 1,0 - A5), com desvio padrão menores do que as médias. No entanto, os docentes da ZR (média 0,25) ressaltaram que esse tempo não é suficiente (A6), enquanto que os docentes da ZU apresentaram uma média de 1,0, o que nos mostra uma pequena diferença, sendo a partir do desvio padrão que percebemos que a diferença da média possui valor significativo para afirmarmos que os docentes da $\mathrm{ZU}$ dispõem de mais tempo para o planejamento do que os docentes da Zona Rural.

A partir desta discussão e dos resultados obtidos no primeiro bloco, afirmar-se ainda, que as metodologias utilizadas podem contribuir para atender potencialmente aos objetivos pré-estabelecidos pelo docente que 
estão preocupados em possibilitar aos discentes, um dos principais sujeitos do ensino, situações favoráveis à aprendizagem. Percebe-se também que, apesar das instituições escolares buscarem e incentivarem a inovação por parte dos docentes (A4), estas mesmas instituições não disponibilizam um tempo necessário para os docentes se apropriarem dos recursos e metodologias alternativas (A6).

Sabe-se que as áreas de Ciências da Natureza e Matemática e suas Tecnologias são vistas como áreas que apresentam dificuldades no processo de ensino e de aprendizagem, com bases na literatura. Isso é decorrente da prática docente centrada neste Ensino Tradicional, tachada como enciclopédica, a qual considera o aluno como o objeto que apreenderá o conceito a ser repassado. O uso de metodologias alternativas faz-se necessário não só para superar esse tipo de prática de ensino, mas também para possibilitar que nossos alunos desenvolvam suas habilidades críticas e reflexivas.

\subsection{As metodologias alternativas no processo de efetivação da aprendizagem}

Os dados referentes a segunda categoria de análise, "As metodologias alternativas no processo de efetivação da aprendizagem" (A7 - A15), estão representados na Figura 3 e Tabela 2.

Tabela 2: Dados obtidos da Zona Rural e Urbana - Categoria 02

\begin{tabular}{ccc}
\hline Assertivas & $\begin{array}{c}\text { Concepções- } \\
\text { Zona Rural } \\
\text { (Média } \circ \text { Desvio) }\end{array}$ & $\begin{array}{c}\text { Concepções- } \\
\text { Zona Urbana } \\
\text { (Média } \circ \text { Desvio) }\end{array}$ \\
\hline A7 & $1,50 \circ 0,50$ & $1,73 \circ 0,43$ \\
A8 & $-0,75 \circ 0,50$ & $0,45 \circ 0,93$ \\
A9 & $-0,25 \circ 1,50$ & $0,18 \circ 1,47$ \\
A10 & $1,00 \circ 0,00$ & $1,27 \circ 0,47$ \\
$\mathrm{~A} 11$ & $2,00 \circ 0,00$ & $1,30 \circ 0,65$ \\
$\mathrm{~A} 12$ & $2,00 \circ 0,00$ & $1,09 \circ 0,94$ \\
$\mathrm{~A} 13$ & $1,00 \circ 0,00$ & $1,36 \circ 0,67$ \\
$\mathrm{~A} 14$ & $1,00 \circ 0,00$ & $1,18 \circ 0,75$ \\
$\mathrm{~A} 15$ & $1,25 \circ 0,50$ & $1,20 \circ 0,75$ \\
\hline
\end{tabular}

Fonte: Produzido pelos autores (2017)

O segundo bloco da escala de Likert (A7- A15) foi destinado para avaliarmos como os docentes compreendem as metodologias alternativas no processo de aprendizagem. Os docentes entrevistados apontam que o uso das metodologias alternativas influencia diretamente na aprendizagem dos alunos (médias ZR 1,50, ZU 1,73) (A7). Porém, defendem que somente o uso dessas metodologias são insuficientes para superar as limitações do Ensino Tradicional (médias: ZR -0,75, ZU 0,45) (A8).

Os desvios padrão dessas assertivas foram menores do que a média, o que nos indica que os respondentes tiveram opiniões semelhantes ao valor esperado. Quanto ao uso contínuo de metodologias tradicionais com instrumento que dificultará a aprendizagem dos alunos (médias: ZR -0,25, ZU 0,09), os docentes discordam de tal afirmação (A9), porém apresentando valores de desvio padrão muito maiores do que a média, o que nos diz, que houve uma elevada dispersão entre os dados obtidos. A partir dos dados obtidos podemos ainda afirmar que para os docentes, participantes da pesquisa, as metodologias alternativas são instrumentos indispensáveis ao processo de ensino e de aprendizagem (médias: ZR 1,0, ZU 1,27) (A10), não apresentando variação no desvio padrão para os docentes da Zona Rural e um valor abaixo da média para os dados dos docentes Zona Urbana.

Neste bloco de dados, destaca-se a importância das concepções docentes quanto à interferência das metodologias diferentes do convencional na construção de conhecimentos. Isto se faz de extrema importância para a mobilização de atitudes que favoreçam o uso destas metodologias, por parte dos docentes, no processo de ensino e de aprendizagem para efetivação da aprendizagem.

A discussão sobre as metodologias tradicionais, mencionadas pelos docentes como metodologias que não dificultam a construção de conhecimentos do aluno, trata-se de metodologias que são habituais nas práticas de Ensino. Neste caso, tratamos da perspectiva da necessidade da criação (ou interação) de subsunçores na estrutura cognitiva do aluno que, quando não os tem, ou não conseguem dar significado ao assunto que está sendo ministrado, acaba aprendendo de forma mecânica e não significativa. Assim, as metodologias tradicionais que são muitas vezes voltadas para a memorização dos conteúdos, acabam promovendo uma maior necessidade do próprio aluno de dar significados aos conteúdos estudados.

Enfatiza-se que não nos cabe aqui definir o certo ou o errado no ensino, mas sim, entender e perceber sinais da aprendizagem significativa, a partir das realidades vividas no âmbito escolar na perspectiva docente e dos diálogos entre professor-aluno à luz da teoria. Neste caso, as metodologias alternativas surgem como instrumentos potencialmente significativos que podem vir a atender as condições da aprendizagem significativa, sendo estas: o material de aprendizagem potencialmente significativo e a disposição para aprendizagem 


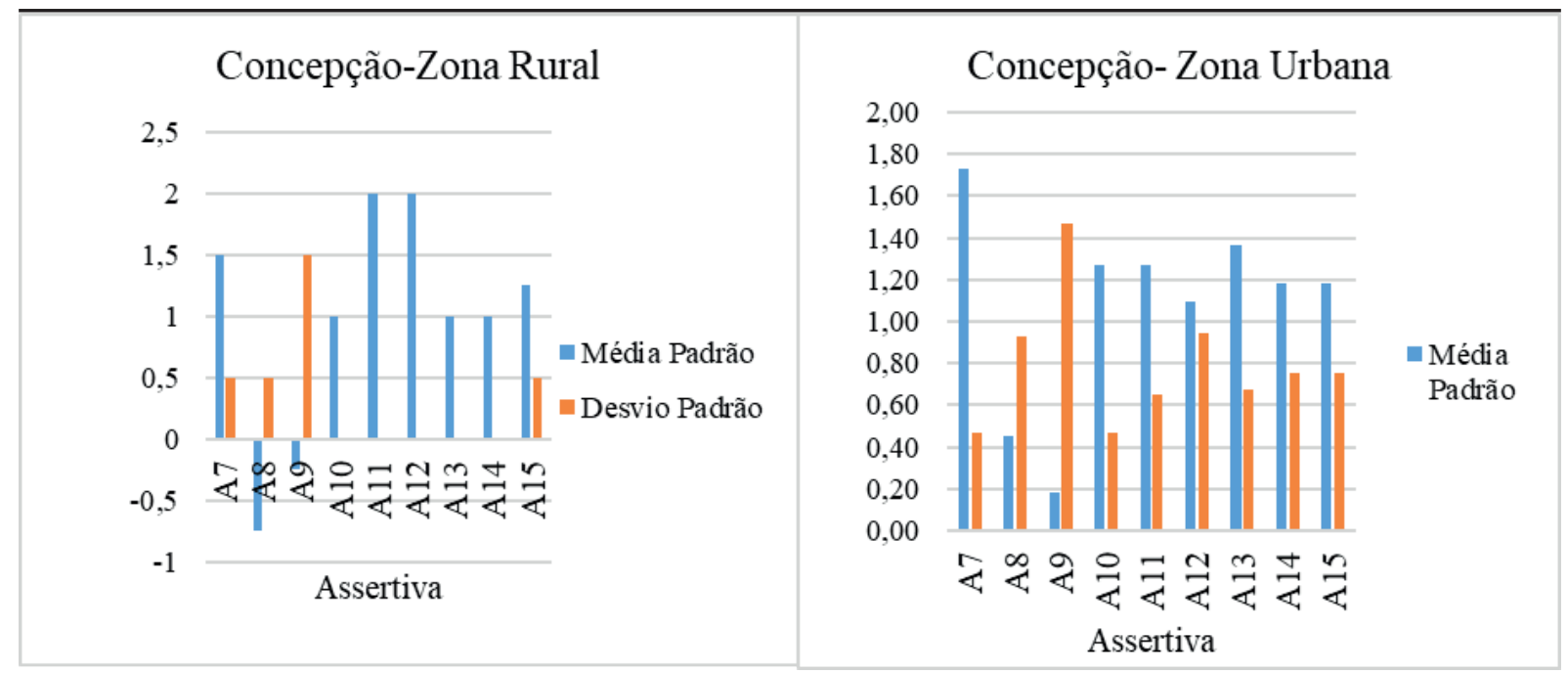

Figura 3: Concepções dos docentes da Zona Rural e Urbana - Categoria 02 Fonte: Produzido pelos autores (2017).

por parte do aprendiz (MOREIRA, 2011).

Quanto à assertiva de que, utilizando de materiais diferentes do modelo habitual para o ensino do conteúdo programático do ensino médio é uma alternativa para despertar o interesse dos alunos, os docentes da ZR, média 2,0, apresentaram uma média de afirmação maior do que os da ZU, média 1,27 (A11), sem variações para o desvio padrão para a Zona Rural e um valor menor que a média para a Zona Urbana, que indica que não houve grande dispersão entre os respondentes.

De uma forma geral, é importante destacar que, a partir das médias obtidas frente a assertiva 11, as concepções dos docentes em relação ao uso de materiais alternativos com instrumentos de metodologia diferenciada é de grande valor para o auxílio da sua prática. Entendemos, que a motivação dos discentes deve estar dentro do objetivo do professor como mediador do processo de construção de conhecimento, pois não se constrói, não se desenvolve e não se consolida conhecimento quando não se tem essa intenção.

Os docentes afirmaram ainda que as aulas com metodologias alternativas instigam a curiosidade e o desejo de aprender dos alunos (médias: ZR 1,75, ZU 1,18) (A12), por ser algo diferente do que estão acostumados e por serem elementos mobilizadores de práticas inovadoras (médias: ZR 1,0, ZU 1,36) (A13), além de auxiliarem nos processos cognitivos (médias: ZR 1,0, ZU 1,18) (A14). Isso porque, a metodologias apresentadas ao aluno podem influenciar o comportamento deste aluno quanto ao seu desejo de aprender e permitir a or- ganização de subsunçores relevantes ao tema abordado para, possivelmente, ocorrer a integração entre a nova informação com o subsunçor em sua estrutura cognitiva.

Quanto à assertiva de que a metodologia alternativa é uma ferramenta que contribui na tarefa de ensinar e de aprender, os docentes tiveram considerações semelhantes, com médias ZR 1,25 e ZU 1,18 (A15). Os desvios Padrão das assertivas A12, A13, A14 e A15, obtiveram valores menores do que a média, sendo que os respondentes foram condizentes em seus resultados, ressaltamos os valores dos desvio padrão das A12, A13 e A14 da Zona Rural, igual a zero, que não apresentaram variação.

Estes resultados vão ao encontro das nossas expectativas, quando temos como referências diversos autores que, em seus trabalhos, defendem a utilização de metodologias alternativas, como exemplos mencionados na fundamentação teórica deste trabalho. Além do mais, as metodologias alternativas são elementos mobilizadores para uma aprendizagem significativa, por serem ferramentas potencialmente significativas. As concepções docentes sobre as metodologias alternativas nos confirma a preocupação deles quanto à aprendizagem dos discentes.

Neste bloco da escala de Likert percebe-se que para os docentes as metodologias alternativas são ferramentas que auxiliam o processo de ensino-aprendizagem, possibilitando o desenvolvimento de aulas inovadoras, atrativas, motivacionais e indutivas no processo de 
construção de conhecimento. Acredita-se que outros fatores estejam relacionados com a limitação do ensino que não visa a inovação, como por exemplo, a falta de reconhecimento profissional, remuneração correspondente a dedicação exclusiva do professor e, principalmente, a falta de tempo para a planejamento e elaboração de metodologias diferentes da convencional, como mencionado no trabalho de Paro (2012), citado anteriormente. Isso pode resultar na desmotivação e na desistência da busca por alternativas diferenciadas para atrair a atenção do aluno para o processo de aprendizagem.

Porém, é importante destacar que os docentes atribuem valor para o uso de metodologias de Ensino Tradicional, não desconsiderando a importância para a aprendizagem dos alunos, até por que nenhuma metodologia será completa e sim complementares entre si, mas é necessário destacar, que a metodologia tradicional de ensino apresenta algumas lacunas e, segundo Hoehnke, Koch e Lutz (2005), pode levar a vários problemas como, por exemplo, a imitação, submissão, repetição, controle total do aluno pelo professor e atividades muito divergente do cotidiano do aluno.

\subsection{As atitudes dos docentes quanto o uso de me- todologias alternativas}

Os dados referentes a terceira categoria de análise, "As atitudes dos docentes quanto o uso de metodologias alternativas" (A16 - A21), estão representados no Figura 4 e Tabela 3.

Tabela 3: Dados obtidos da Zona Rural e Urbana - Categoria 03

\begin{tabular}{ccc}
\hline Assertivas & $\begin{array}{c}\text { Concepções- } \\
\text { Zona Rural } \\
\text { Média } \circ \text { Desvio) }\end{array}$ & $\begin{array}{c}\text { Concepções- } \\
\text { Zona Urbana } \\
(\text { Média } \circ \text { Desvio })\end{array}$ \\
\hline $\mathrm{A} 16$ & $1,00 \circ 0,80$ & $1,00 \circ 0,63$ \\
$\mathrm{~A} 17$ & $1,25 \circ 0,50$ & $1,00 \circ 0,63$ \\
$\mathrm{~A} 18$ & $1,25 \circ 0,50$ & $1,00 \circ 0,63$ \\
$\mathrm{~A} 19$ & $0,25 \circ 0,96$ & $0,91 \circ 0,94$ \\
$\mathrm{~A} 20$ & $1,25 \circ 0,50$ & $0,91 \circ 0,54$ \\
$\mathrm{~A} 21$ & $1,25 \circ 0,50$ & $0,91 \circ 0,94$ \\
\hline
\end{tabular}

Fonte: Produzido pelos autores (2017)

Com último bloco da escala de Likert (A16 - A21), pretende-se avaliar a opinião dos docentes quanto o uso (ou possível uso) de algumas metodologias alternativas. Inicialmente, avaliamos a assertiva de que a utilização de materiais alternativos proporciona aos professores reformulação da sua própria prática de ensino e criação de uma nova concepção sobre o ensino tradicional. Segundo as médias obtidas: ZR 1,0, ZU 1,0 (A16), considera-se como verdadeira e destacamos que o uso de materiais alternativos caracteriza uma metodologia diferente do convencional, objetivando a construção da aprendizagem. Posteriormente, os docentes destacaram a importância da realização de pesquisa em livros e na internet como uma metodologia (médias: ZR 1,25, ZU 1,0) (A17), bem como a realização de experimentação (médias: ZR 1,25, ZU 1,0) (A18).

Compreende-se que os docentes conhecem essas ferramentas, com seu uso na prática, prevalecendo sua utilização como ferramenta de aprendizagem disciplinar e que o uso de tais metodologias são eficazes para superar algumas lacunas deixadas pelo ensino tradicional como, por exemplo, o entendimento de que ensinar é repassar informação solta e sem significado. Pauta-se as discussões nos valores do desvio padrão das assertivas A16, A17, A18 de valores inferiores aos das médias, significando que os valores das assertivas são mais homogêneos entre os respondentes.

Quanto à utilização de aulas de campo como uma metodologia alternativa, os docentes destacam que esta metodologia não é utilizada com frequência e que o desejo da realização de aulas de campo durante as aulas da área de Ciências da Natureza e Matemática não é no geral acentuado, (médias: ZR 0,25, ZU 0,9) (A19), com valor do desvio padrão maior do que a média, indicando uma dispersão entre os valores dos respondentes. Acreditamos que este fato, a pouca ou nenhuma utilização de aulas de campo, deve-se pela falta de assistência e recurso destinado para atividade extra sala de aula, temos como base este fator pela vivência da autora do presente trabalho na escola campo de pesquisa da Zona Rural.

Quanto à concepções docente sobre o uso da abordagem da relação entre Ciência-Tecnologia-SociedadeCTS como uma metodologia alternativa e em relação a utilização de Web site como forma de facilitar o acesso dos alunos aos conteúdos programáticos e motivá-los quanto sujeitos do processo de aprendizagem, obtevese os mesmos resultados médios: ZR 1,25, ZU 0,9 nas assertivas 20 e 21 (A20 e A21), com desvio padrão menores do que as médias, exceto a A21 da Zona Urbana, que apresenta uma pequena dispersão entre os valores dos respondentes.

A média obtida nos revela que os docentes da Zona Rural tem a preocupação maior em abordar a relação CTS e o uso de Web site, do que os docentes da Zona Urbana, mesmo a diferença não sendo muito relevante. Este resultado nos chama a atenção por acreditar-se, inicialmente, que os discentes da Zona Rural possuíam menor acesso à Internet do que os alunos da cidade que 


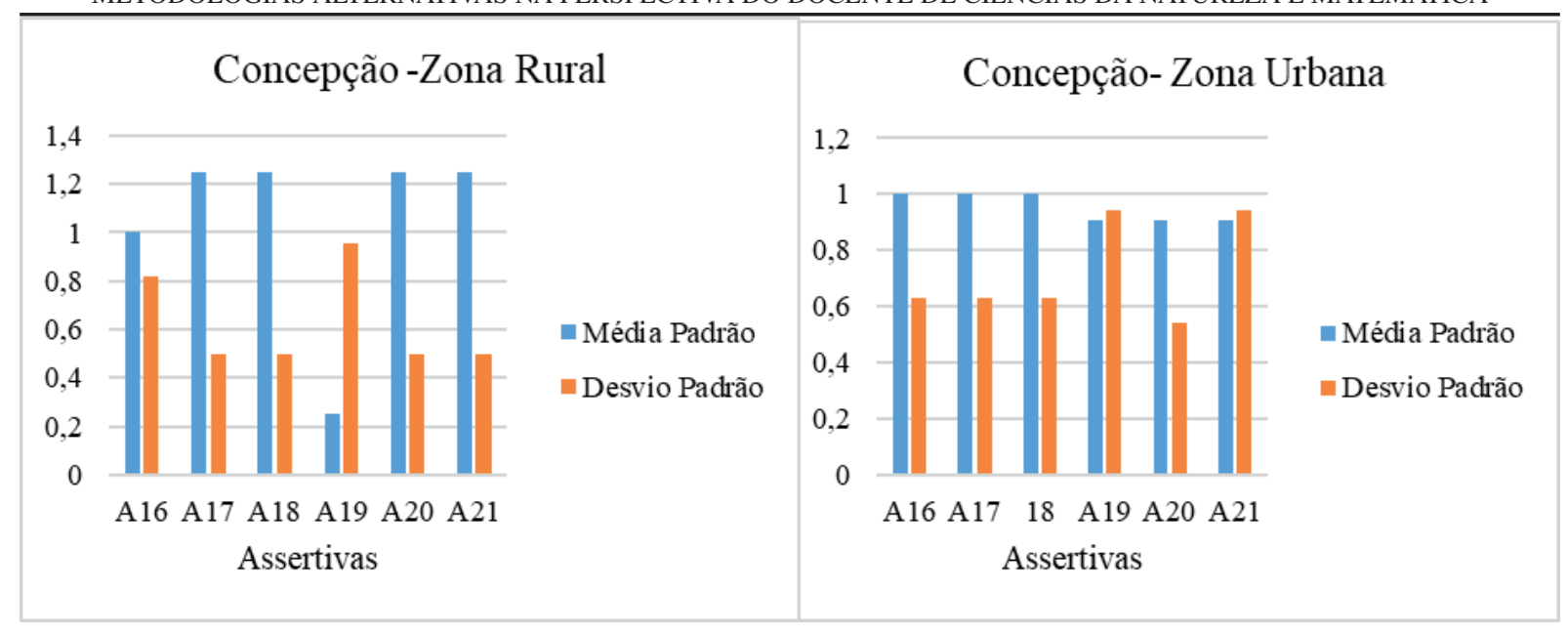

Figura 4: Concepções dos docentes da Zona Rural e Urbana - Categoria 03 Fonte: Produzido pelos autores (2017).

possuem diversos locais de acesso livre. Estas metodologias alternativas são de extrema importância para o público de alunos do século XXI, visto que os avanços tecnológicos e suas influências encontram-se em ampla discussão no âmbito acadêmico e social. Isso justifica o nosso interesse em questionar as concepções dos docentes sobre tais metodologias, mesmo não sendo exemplos mencionados na fundamentação teórica e em outro momento deste trabalho.

De um modo geral, o terceiro e último tópico da pesquisa vem nos reafirmar o que já havíamos constatado anteriormente, que a utilização de metodologias alternativas são direcionamentos para uma prática inovadora e conjunto de ferramentas que auxilia ao professor em sua prática docente. Destaca-se ainda que existem diversas metodologias alternativas que podem ser utilizadas em sala de aula, porém, cabe ao docente definir qual deve ser utilizada em sua aula, sala, escola e contexto.

Neste ponto, acredita-se na existência de fatores que podem influenciar nesta escolha para atender às necessidades educacionais dos alunos. Deve-se inicialmente levar em consideração a realidade social e cultural do aluno, bem como, as condições que a instituição oferece para o desenvolvimento da metodologia e, principalmente, deve-se questionar: i) a metodologia escolhida atende a necessidade de meus alunos? ii) é conveniente para a realidade da minha escola? iii) a escola disponibiliza de recursos materiais necessários para o desenvolvimento de tal metodologia? Estes questionamentos devem ser seguidos de um planejamento de toda a prática, a fim de elaborar, re-elaborar e relacionar o conteúdo programático com estes instrumentos para que o docente não caia na ilusão do "usar por usar", e sim, desenvolva uma prática diferente do habitual e que atenda os objetivos esperados, a motivação do alunado em aprender e a utilização de materiais potencialmente significativos, visando o aluno como um dos principais sujeitos do processo de ensino e de aprendizagem. Se não for assim, a metodologia, por mais que seja diferente, possivelmente não contribuirá para a construção de significados dos conteúdos abordados, podendo colocar o professor em situação desfavorável e frustrante de não obtenção de resultados positivos por falta de adequação da metodologia utilizada como o contexto escolar em específico.

\section{CONCLUSÃO}

Diante do observado por meio do instrumento utilizado nesta pesquisa, escala de Likert, pode-se inferir que os docentes participantes apontam a utilização de metodologias alternativas para o auxílio nos processos cognitivos do aluno, bem como, na motivação, construção, consolidação do conhecimento mediado em sala de aula pelos docentes. Além disso, sua utilização é um apoio para a superação das limitações do ensino tradicional, proporcionando ainda ao professor a reformulação da sua prática, visando o "bom ensino", caracterizado pela ação docente que atenda as dimensões da aprendizagem e vise uma aprendizagem significativa.

Destaca-se ainda que uma formação inicial e continuada dos docentes voltada para uso dessas metodologias é de grande importância e influenciam diretamente 
na sua prática em sala de aula. Vale ainda pontuar, que o trabalho do professor é diretamente sugestionado pelas condições oferecidas pela instituição de ensino em sua totalidade, tais como: a assessoria pedagógica, com o importante papel de apoio ao docente no sentido amplo da palavra e que vai muito além da supervisão da qualidade do trabalho docente; a falta de tempo para o planejamento das aulas que visem à utilização de metodologias diferenciadas, outra questão que merece destaque em nossas considerações, pois acreditamos que o tempo extra sala de aula é algo essencial ao trabalho docente para o planejamento das prática inovadoras e o desenvolvimento de um "bom ensino", entre outras. Muitas vezes, a falta de tempo para planejamento de tal atividade torna-se um fato, segundo os docentes pesquisados, contraditório ao desenvolvimento dos objetivos educacionais escolares que, por sua vez, defende a prática docente como mediadora do conhecimento, onde o professor e o aluno devem ser entendidos como sujeitos do ensino.

Tais inferências vão ao encontro com o trabalho de Paro (2012) que destaca que existem inúmeras questões que merecem atenção sobre o trabalho coletivo escolar. Entre outras questões, o autor destaca assistência pedagógica e a gestão do tempo, devido a sua abrangência e importância.

\section{REFERÊNCIAS}

ARROYO, M. G.; CALDART, R. S.; MOLINA, M. C. Por uma educação do campo. 1. ed. Petrópolis: Vozes, 2004.

BRASIL. Lei de diretrizes e bases. Lei no 9.394/96, de 20 de dezembro de 1996. 1996.

Parâmetros Curriculares Nacionais. 1. ed. Brasília: MEC/SEF, 1998.

CASTRO, B. J. d.; COSTA, P. C. F. Contribuições de um jogo didático para o processo de ensino e aprendizagem de química no ensino fundamental segundo o contexto da aprendizagem significativa. Revista electrónica de investigación en educación en ciencias, SciELO Argentina, v. 6, n. 2, p. 25-37, 2011.

COSTA, S. F. Estatística aplicada à pesquisa em educação. 1. ed. Brasília: Liber livro, 2010. P.91.

FÁVERO, M. L. A. Em Formação de professores: pensar e fazer. 1. ed. São Paulo: Cortez, 1992.

FREIRE, P. Pedagogia da autonomia: saberes necessários à prática educativa. Ed. Paz e Terra, Coleção Leitura. 1996.
GARCÍA, J. E.; GALÁN, T. R. La medida de las actitudes usando las técnicas de likert y de diferencial semántico. Enseñanza de las ciencias: revista de investigación y experiencias didácticas, v. 16, n. 3, p. 477-484, 1998.

HOEHNKE, K.; KOCH, V.; LUTZ, U. O objectivismo na filosofia e na metodologia do ensino. Lisboa. 2005.

LEITE, S. C. Escola rural: urbanização e políticas educacionais. 1. ed. São Paulo: Cortez, 1999.

LOUSADA, E. Os pequenos grandes impedimentos da ação do professor: entre tentativas e decepções. In: MACHADO, A. R. (Ed.). O ensino como trabalho: uma abordagem discursiva. 1. ed. Londrina: Eduel, 2004. p. 271-296.

MACHADO, A. R. Trabalho prescrito, planificado e realizado na formação de professores: primeiro olhar. 1. ed. Belo Horizonte: Scripta, 2003.

MORAN, J. M.; MASETTO, M. T.; BEHRENS, M. A. Novas tecnologias e mediação pedagógica. 10. ed. Campinas: Papirus, 1006.

MOREIRA, M. A. Aprendizagem significativa: a teoria e textos complementares. 1. ed. São Paulo: Editora Livraria da Física, 2011.

NUNES, A. S.; ARDONI, D. S. O ensino de química nas escolas da rede pública de ensino fundamental e médio do município de itapetinga-ba:. O Olhar dos Alunos. 2009.

PARO, V. H. Trabalho docente na escola fundamental: questões candentes. Cadernos de Pesquisa, Fundação Carlos Chagas, v. 42, n. 146, p. 586-611, 2012.

PELIZZARI, A.; KRIEGL, M. d. L.; BARON, M. P.; FINCK, N. T. L.; DOROCINSKI, S. I. Teoria da aprendizagem significativa segundo ausubel. revista PEC, v. 2, n. 1, p. 37-42, 2002.

PIMENTA, S. G. Saberes pedagógicos e atividade docente. 1. ed. São Paulo: Cortes, 1999.

SILVA, M. C. M. O primeiro ano de docência: o choque com a realidade. In: ESTRELA, M. T. (Ed.). Viver e construir a profissão docente. Portugal: Porto Editora, 1997. p. 51-80.

TARDIFF, M. Saberes docentes e formação profissional. 2. ed. Petrópolis: Vozes, 2002. 
UNESCO. A ciência para o século XXI: uma nova visão e uma base de ação. 2005. Disponível em: < http:

//www.slideshare.net/ProfessorAdalbertoAzevedo/

cinciaparaosc-xxi-unesco $>$.

ZABALZA, M. A. O ensino universitário: seu

cenário e seus protagonistas. 1. ed. Porto Alegre:

Artmed, 2004. 